\title{
学术信息与动态
}

DOI: $10.5846 /$ stxb202103070620

尹彩春, 赵文武. 应对气候和生态环境危机 促进全球可持续发展——UNEP 与自然和谐共处报告简述.生态学报, 2021,41(23):9536-9542.

\section{应对气候和生态环境危机 促进全球可持续发展}

\section{UNEP 与自然和谐共处报告简述}

\author{
尹彩春 $^{1,2,3}$, 赵文武 $1,2, *$ \\ 1 北京师范大学地理科学学部地表过程与资源生态国家重点实验室, 北京 100875 \\ 2 北京师范大学地理科学学部陆地表层系统科学与可持续发展研究院, 北京 100875 \\ 3 北京林业大学水土保持学院, 北京 100083
}

摘要:2021 年 2 月 18 日,联合国环境署发布《与自然和谐共处:应对气候、生物多样性和污染危机的科学蓝图》。报告指出:气 候变化、生物多样性下降和环境污染已经成为全球三大环境紧急情况; 人与自然关系面临着社会经济发展压力加剧环境风险、 遏制环境恶化的全球承诺尚未兄现、环境风险威胁可持续发展目标等多重挑战; 全球亟需开展以联合国可持续发展目标为框架 的系统变革, 加快应对全球环境危机的重点行动, 改革资源环境和经济系统, 提高粮食、能源和水系统的环境友好性与可持续 性,加强对人体健康与生态环境健康的协同保护,进而推动人与自然的和谐共处以及可持续发展。该报告结合全球环境评估的 最新进展,强调了社会-经济-环境可持续发展仍是未来的重要研究课题,对我国社会-生态系统与可持续发展等领域的科学研究 有如下启示: (1) 创新社会-生态系统的综合集成研究,探寻不同发展路径和气候变化情景下社会-生态系统时空演变特征与趋 势; (2) 注重科学研究对决策的支撑以及与国际重大议程的衔接, 探索和创新可持续发展的中国方案。

关键词:气候变化; 生物多样性下降; 环境污染; 可持续发展

全球环境变化和可持续发展是 21 世纪的两大重要科学议题和挑战,而气候变化、生态破坏和环境污染已 成为阻碍可持续发展的三大风险源。2021 年 2 月 18 日,在第五届联合国环境大会到来之际,联合国环境署 (United Nations Environment Programme, UNEP) 发布了其首份综合报告《与自然和谐共处:应对气候、生物多 样性和污染危机的科学蓝图 $\rangle^{[1]}$ 。该报告集成了政府间气候变化专门委员会 ( Intergovernmental Panel on Climate Change, IPCC)、生物多样性和生态系统服务政府间科学-政策平台 (Intergovernmental Science-Policy Platform on Biodiversity and Ecosystem Services, IPBES)、地球观测组织 (Group on Earth Observations, GEO) 等 机构最新的全球环境评估成果,分析了人与自然关系的现状与挑战,并提出了应对策略, 旨在协同应对气候变 化、生物多样性下降和环境污染三大危机, 推动实现 2030 年议程及 17 项可持续发展目标 (Sustainable Development Goals, SDGs)，进而实现人与自然的和谐共处以及可持续发展。

\section{1 人与自然关系的现状与挑战}

\section{1 社会经济发展压力加剧环境风险}

受人口增长、城市化以及资源密集型发展模式的影响, 以生态系统退化为代价的土地利用/覆被变化加 速, 自然资源的开采和消耗量大幅增加。1 970 年以来, 全球人口增长了一倍多, 全球经济和贸易分别增长了

基金项目:国家自然科学基金(42042026)

收稿日期:2020-10-30; 采用日期:2021-04- 16

* 通讯作者 Corresponding author.E-mail: zhaoww@ bnu.edu.cn 
近 5 倍和 10 倍 ${ }^{[2]}$, 使得原材料的开采以及一次能源和粮食的生产都增加了两倍多 ${ }^{[3]}$ 。人类正在加速改变自 然生态系统, 全球一半的土地处于人类主导的半自然状态; $25 \%$ 的土地已被彻底转换为农田、建设用地和其他 人为景观; 只剩下约 $25 \%$ 的土地保持着几乎未受人类干扰的自然状态 ${ }^{[3]}$ 。到 2050 年, 全球人口预计将从目 前的 78 亿增加到近 90 亿, 伴随着经济发展和城市化的巨大需求, 能源产量将增加约 $50 \%{ }^{[4]}$, 粮食产量增加约 $70 \%{ }^{[1]}$ 。高强度的资源使用和废弃物排放不仅会威胁当地的生态环境安全, 还会在国家间和大陆间流动, 进 而加剧全球环境变化。土地退化也面临难以逆转的危机, 预计到 21 世纪中叶, 近自然状态的土地将缩减至 $10 \%$, 而退化的土地将超过 20\%。尤为重要的是, 生态系统状态的改变将导致生态过程和服务的退化, 目前六 分之一的人为改造土地已经出现了与人类福祉相关的生态系统功能退化 ${ }^{[3,5]}$ 。

社会经济发展高度依赖于自然资源和环境基础, 以及供给、调节、支持和文化等生态系统服务。然而, 目 前的经济和金融体系将自然的价值及其退化的代价排除在经济核算和市场价格之外,尚缺乏促进可持续利用 和保护自然的激励措施。传统的核心经济指标, 如国内生产总值(GDP), 忽视了自然资源等生态资产的价值 和收益, 也未能考虑生态退化和环境污染的外部性和成本。此外, 由于目前的大部分经济核算体系强调量的 “增长”, 而未能充分反映质的 “发展”,加上短期、既得利益对不可持续性投资方向的驱动, 目前的社会经济发 展模式正在加剧全球环境风险 ${ }^{[6]}$ 。

\section{2 遏制环境恶化的全球承诺尚未兄现}

世界还未走上控制全球变暖的正轨。IPCC 指出, 全球变暖超过工业化前水平 $1-2^{\circ} \mathrm{C}$ 时, 气候系统的状 态可能逼近临界点而发生不可逆转的变化 ${ }^{[7]}$ 。《黎协定》要求, 气候变暖幅度应当被控制在工业化前水平 的 $2^{\circ} \mathrm{C}$ 以内, 并且全球应为升温幅度不超过 $1.5^{\circ} \mathrm{C}$ 而努力 ${ }^{[8]}$ 。然而, 各国对控制全球变暖做出的努力参差不 齐。与 19 世纪末相比, 目前地球近地表平均温度已经上升 $1^{\circ} \mathrm{C}$ 以上。按照目前的速度, 全球变暖幅度将在 2040 年左右达到 $1.5^{\circ} \mathrm{C}$, 在 2100 年至少会上升 $3^{\circ} \mathrm{C}^{[9]}$ 。

保护地球生物的全球行动未充分落实。在 20 项爱知生物多样性目标中, 只有 6 项目标得以实现 ${ }^{[10]}$, 例 如, 增加陆地和海洋保护区的面积。目前物种灭绝的速度比自然背景下快几十到数百倍, 全球约 800 万种动 植物中有 100 万种濒临灭绝。1 1970 年以来, 野生脊椎动物和昆虫物种的数量分别下降了 $68 \%$ 和 $50 \%$ 。由 于土地利用变化、气候变化、环境污染和外来物种入侵,生态系统正在以前所未有的速度退化。

治理环境污染还需加快步伐。世界对臭氧层的修复富有成效, 如果各国按照《蒙特利尔议定书》的协议 继续对消耗臭氧层的化学品进行生产和消费上的限制, 到 21 世纪中叶, 臭氧层就可能恢复到 1980 年前的水 平 $^{[11]}$ 。然而, 目前的环境污染治理依旧面临众多挑战。全球每年有多达 4 亿 $\mathrm{t}$ 的重金属、有毒污泥和其他工 业废物被排人水域; 海洋塑料污染自 1980 年以来增加了 10 倍 ${ }^{[12]}$; 近几十年来大气污染问题在高收人国家有 所改善, 但大多低收人国家的情况继续恶化, 全球一半以上的人口仍暴露于严重的大气污染环境中 ${ }^{[13]}$ 。因 此, 全球依旧亟需加快减轻环境污染和安全管理废弃物的行动。

\section{3 环境风险威胁联合国可持续发展目标的实现}

17 项 SDGs 是到 2030 年实现经济增长、社会包容与环境可持续性的全球发展愿景, 然而, 目前和预计未 来的气候变化和生态环境退化 (SDG 13-15) 使 SDGs 的进展面临巨大阻碍 (图 1)。全球变暖伴随着极端天 气事件的频发和旱涝格局的改变, 阻碍着减贫、粮食和农业安全、人类健康和供水安全等目标的进展 (SDG 1-3、6), 并使城市基础设施的安全面临威胁 (SDG 9、11)。环境退化可能加剧性别间和国家间的不平等 (SDG 5、10), 特别是在人口生计依赖于自然资源的农村地区, 妇女难以平等获得资源、土地、教育等权利; 由 于低收人国家的发展高度依赖于农业等气候敏感部门,这些国家也承受着最沉重的气候变化压力。能源和生 产消费可持续性、经济增长和体面工作 $($ SDG 7、8、12) 的进展将受到自然资本流失和气候变化的阻碍, 全球约 32 亿人已经受到土地退化的不利影响, 仅 2018 年, 气候相关自然灾害造成的损失就达 1550 亿美元 ${ }^{[14]}$ 。此 外, 环境危机可能加剧移民和自然资源竞争, 全球因此引发的冲突目前已超过 2500 起 $^{[15]}$, 严重危及和平与包 容社会的发展(SDG 16、17)。 


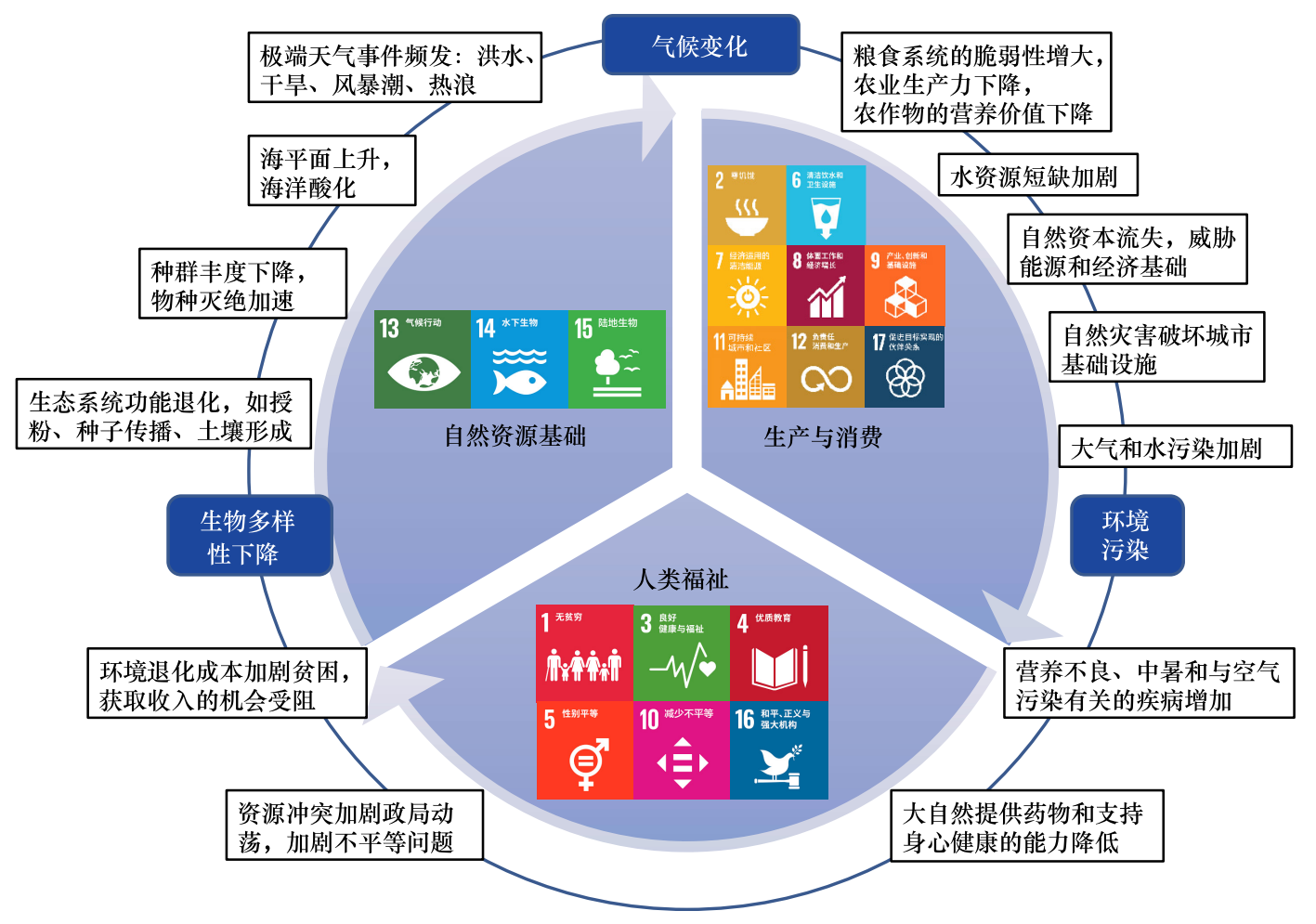

图 1 环境风险对可持续发展目标的影响 (根据参考文献 [1]修改)

Fig.1 Impact of environmental risks on sustainable development goals

\section{2 促进人与自然和谐共处的路径}

2.1 推动以可持续发展目标为框架的系统变革

以 17 项 SDGs 为框架,协同推动社会、经济和环境可持续发展,在价值观念、政策、教育、技术、经济、协 作、环境等方面进行系统性的变革, 并综合协调短期利益与长期利益。由于短期和既得利益的驱动以及现有 基础设施和已投人资本的惯性,面向绿色转型和环境保护等方面的投资与变革往往受到阻碍。对此,需要加 强政治领导、媒体宣传和公众监督来营造公平和可持续的竞争环境,使破坏生态和污染环境的产业部门无法 通过外部化环境成本来获得竞争优势; 充分发挥环境监测、环境影响评价、奖惩激励机制等措施的导向作用; 加强跨部门的协作管控,系统规划和管理自然资源; 完善法律法规和司法程序,保证开发建设活动符合环境保 护要求。此外,知情、公平和参与式的治理体系是系统变革的基础, 需要加强政府、国家部门等领导核心的调 控作用,并激励非政府组织、科学教育机构、私营部门、金融机构、媒体、社会团体和家庭在各自的领域内发起 倡议和落实可持续发展行动。

2.2 加快应对全球环境危机的重点行动

由于地球圈层间强大的连通性,气候变化、生态系统退化和环境污染等危机往往相互交织,通过级联作用 被不断放大。为了协同应对全球变化和可持续发展两大挑战, 需要探索并落实基于自然的解决方案 ( Naturebased Solutions, NbS), 减轻多维环境脆弱性, 最大限度地减少权衡并促进协同。例如, 修复天然林、植树造林 等生态修复措施, 可以同时发挥固碳释氧、保护生物多样性、涵养和净化水源等多种效益。

控制气候变化, 亟需深化并加快减排行动。要使全球变暖幅度不超过 $1.5^{\circ} \mathrm{C}$, 二氧化碳净排放量需要在 2030 年之前比 2010 年的水平减少 $45 \%$,并在 2050 年之前达到零排放 ${ }^{[16]}$ 。减排需要对能源、工业、基础设施 和土地管理等部门进行彻底的绿色变革, 并加快研发二氧化碳捕获、储存的技术和设备。减少臭氧、甲烷等气 体的排放量对减缓气候变化也能够发挥重要作用,并有利于改善大气污染、保护公众健康、保障作物产量和粮 
食安全。为了提高气候变化下的适应性和弹性,各国政府应加强对基础设施的投资与建设, 以适应变率增大 的温度和降水模式(如极端干旱、洪涝灾害、海平面上升等)。此外,通过实施基于自然的解决方案, 如海绵城 市、农林复合和水土保持等工程, 不仅可以保护和修复生态, 在减排和控制气候变暖中做出 35\%-40\%的贡 献,也能够产生多种社会经济效益 ${ }^{[3]}$ 。

保护生物多样性,需要明晰并解决导致生物多样性下降的根本和直接原因。生物多样性下降的原因根植 于人类发展的需求之中, 维护生物多样性需要融人对解决贫困、改善生计以及可持续利用粮食、能源等资源的 系统变革中。市场转型和消费观念的提升有利于保护生物多样性, 使其免受贸易和供需链的影响, 例如, 取消 对不可持续性农业、渔业、采矿业的补贴,严格生产标准管理、产品溯源和认证, 并加强消费引导与教育。此 外, 土地和海洋过度开发、气候变化、水污染以及物种人侵等因素直接驱动了生物多样性的下降,遏制生物多 样性下降需同时解决此类环境问题; 加快构建更大范围的陆地和海洋保护区网络,增加对自然保护区监督、执 法和修复方面的投资,并加强对全球保护区间相互作用的研究和改造,使其协同应对气候变化和生态退化 危机。

控制环境污染,需要加强法律法规管控, 以及科学研究成果与政策的衔接。各国需要加强环境影响评价 和环境科学研究,为环境保护决策提供科学基础; 加强法律法规管控并发展净化技术,减少污染物排人大气、 土壤和水域; 此外, 为了加强对环境质量的全球统一评估和管理, 需要在国际和国家层面上制定一套明确的污 染物排放和化学品管理指标体系与标准。

2.3 改革资源环境和经济系统

改革资源环境与经济体系是实现社会-经济-环境协同发展的重要途径。各国应逐步建立自然资本账户， 在国民核算体系中纳人自然资产核算 ${ }^{[17]}$,并对环境保护和破坏行为采取奖惩分明的政策和监管措施。例如， 对污染性的和不可持续的开发建设和生产行为采取关停或征税措施,对低碳和自然友好型的发展模式和技术 提供补贴或经济奖励。此外,政府和企业需要在其管理系统和供应链中将环境成本内部化,并将自然对社会 经济发展的贡献纳人经济衡量指标。根据社会和环境因素(如污染治理成本) 对 GDP 的核算进行修正,使 GDP 在衡量经济发展时更具包容性,能够考虑到支撑社会经济运转的自然资本、环境质量和其他代表发展质 量的非货币因素 ${ }^{[18]}$ 。此外,还需要增加公共和私人筹资, 并引导资金流动和投资方向。优化激励措施, 提供 低成本的融资机会和投资基金,使有利于可持续发展的投资方向更具有吸引力。

2.4 提高粮食、能源和水系统的环境友好性与可持续性

粮食、能源和水是支撑人类生存发展最基础的资源, 也是生态系统为人类提供的关键服务,提高粮食-能 源-水系统的可持续性对于优化人与自然之间的关系至关重要 ${ }^{[19]}$ 。建设有弹性、可持续的农业系统,需要对 粮农产业进行合理的补贴和投资, 为绿色消费模式和可持续农业实践提供动力; 提高农业结构多样性, 形成多 功能农业景观,开发适应盐碱土等条件的品种,加强对有机农业、农林复合、水土保持、病虫害和灌溉等方面的 投资与管理;改善消费和饮食习惯,特别是在肉类和奶制品市场巨大的发达国家,不仅可以减少肉类生产对能 源和水的大量消耗, 还可以减少对生物多样性和气候变化的压力。此外, 减少食物和水的浪费至关重要, 这需 要在从提取、生产、储存、分配基础设施到个人消费观念等领域进行全面的检修与改革。实现可持续用水,需 要提高水利用效率、增加储存水量、促进水源地保护; 优化对城市用水和其他用水主体的管理,完善法律法规 以减少水污染、改善水质、可持续开采地下水; 加强对供水基础设施和废水资源回收项目的投资; 增加对气候 和生物多样性敏感区域的水量储存; 在区域间公平分配水资源还需要跨区协议和政策的引导。能源生产和消 费需向清洁能源和低碳模式转型。到 2050 年实现 $1.5^{\circ} \mathrm{C}$ 的控温目标, 对能源转型的投资需要比目前增加五至 六倍 ${ }^{[5]}$ 。开发风能和太阳能等可再生能源, 促进能源利用技术创新, 提高能源利用效率, 是能源转型的关键 举措。政府应完善政策法规和激励措施, 加快淘汰在发电和交通运输等领域的化石燃料使用。此外, 需要审 慎规划陆地和海洋上的大规模可再生能源装置, 以免对生态系统以及对粮食和水安全产生不利影响。

2.5 加强对人体健康与生态环境健康的协同保护

落实“一个健康 (One health)” 策略,协同促进人体健康和环境健康 ${ }^{[20]}$ 。生态环境的健康和可持续是保障 
人类生存安全与身心健康的基础,控制气候变化可以降低极端天气事件、水媒疾病等风险发生的频率,从而减 少对人类生存安全的威胁; 扭转生态系统退化有助于保障粮食和水安全, 获取药材和生物遗传资源, 并降低人 畜共患疾病爆发的风险; 减少环境污染是预防呼吸系统疾病、保障人体健康的关键。城市是极端高温、洪水、 大气污染、水污染、传染病等环境危机与人体健康之间矛盾最突出的区域, 预计未来 20 年城市将大幅扩 张 ${ }^{[21]}$ 。各国需要加强城市规划, 增强城市弹性; 遵循 $\mathrm{NbS}$ 的理念, 既要保障人类良好的生存空间和发展需求, 也要增强应对气候变化、人畜共患病频发等危机的能力,具体措施包括向低碳经济转型、促进可持续消费和生 产、扩大绿色基础设施等; 沿海城市需要进行合理规划和改造, 以应对海平面上升和海水人侵淡水系统带来的 风险。

\section{3 对我国的启示}

联合国环境署发布《与自然和谐共处》报告, 旨在揭示目前全球面临的环境危机, 呼吁各方积极行动以促 进人与自然可持续发展。更重要的是,该报告揭开了面向人与自然和谐共处的一系列加速行动和重大议程的 序幕( 图 2)。2020 年 SDGs 交付十年之际, 新冠肺炎疫情曼延, 社会经济发展停滞, 这成为人类思考和谋划可 持续未来的窗口期 ${ }^{[22]}$ 。人类发展的持续高压威胁着生态系统安全; 而退化的生态系统及其病毒外溢效应可 能导致新冠肺炎疫情的爆发 ${ }^{[23]}$; 在疫情封锁下, 生态系统在人类活动停滞的空隙中得以暂时修复。这表明生 态系统稳态一旦在人为扰动下突破其临界点,便可能诱发灾难并触发其自适应机制,严重威胁人类的生存与 可持续发展 ${ }^{[24]}$ 。在全球经济萧条、环境退化的危机下,后疫情时期成为协同推进经济复苏与自然修复的巨大 机遇。我国系统及时地控制住了新冠疫情的蔓延, 并率先走上了社会经济复苏的正轨 ${ }^{[25]}$ 。在疫情影响下的 新阶段,我国的社会经济发展应当向可持续的模式转型。发展低碳经济,加快“碳中和” 部署,促进非化石能 源技术的进步与普及; 改善城乡人居环境, 完善环境污染治理体系, 加强对绿色基础设施的投资与建设; 加强 对国家自然保护区的管理,促进生物多样性保护和生态系统修复。

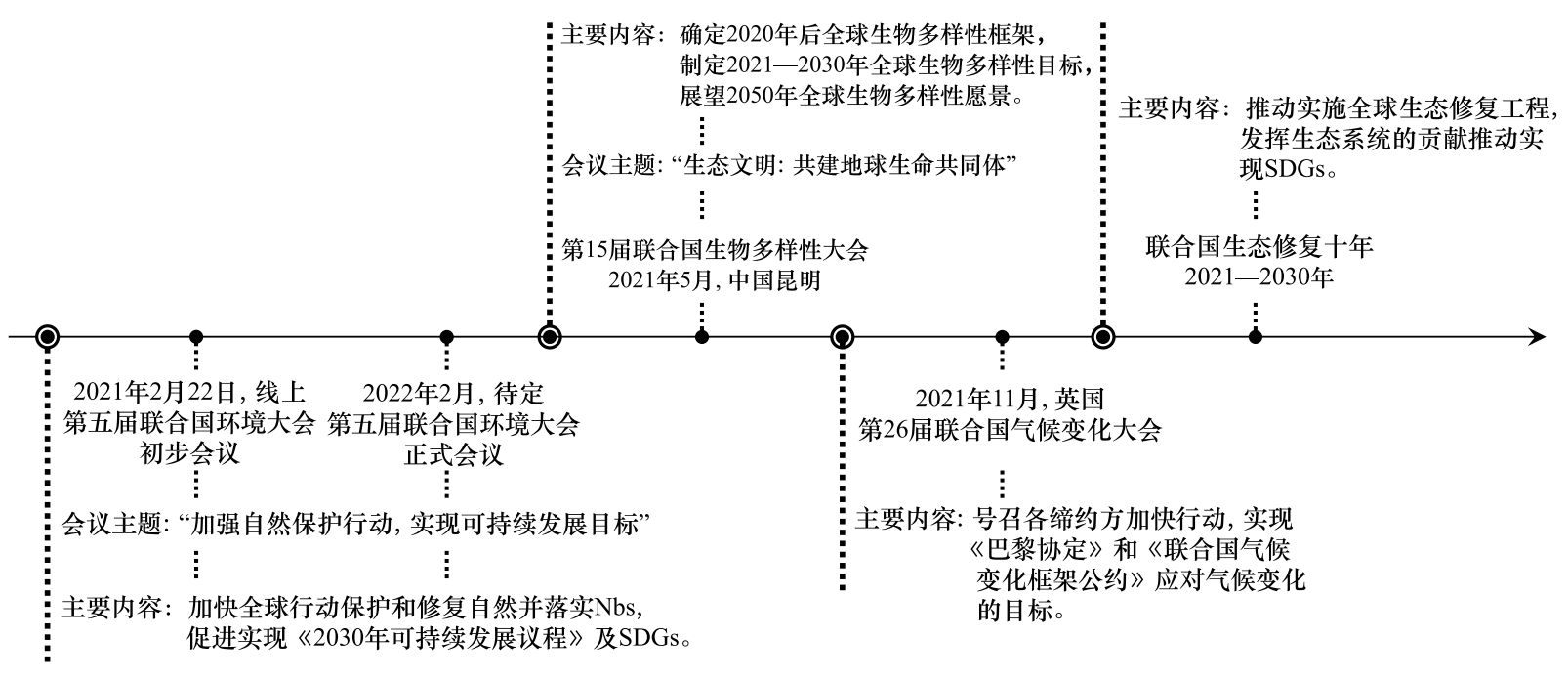

图 2 联合国 2021 年应对气候变化、生物多样性下降和环境污染的主要议程

Fig.2 Key UN agendas to tackle the climate, biodiversity and pollution emergencies in 2021

从联合国主要议程来看, 自然对人类的贡献愈发受到关注, 人地关系和社会-经济-环境的可持续发展仍 是未来的重要课题。中国的快速城镇化、高强度资源开发和污染物排放也威胁着生态环境安全和可持续发 展 ${ }^{[26]}$ 。我国科研工作者需要深化不同时空尺度的社会-生态系统研究并构建发展模型, 开展自然过程与人文 过程中的多要素、多尺度、多过程、多学科和多源数据集成; 在不同的社会经济发展路径和气候变化情景下,探 讨社会-生态系统的脆弱性、恢复力、适应性、承载边界等问题; 重点关注生态系统服务等连接自然-社会经济 
系统的纽带, 量化其供需变化以揭示人地耦合关系演变的机制 ${ }^{[24]}$; 在不同发展路径和情景下, 预警土地利用/ 覆被变化等人类发展需求超越地球界限及社会界限的可能性,并提出调控优化策略 ${ }^{[27-28]}$ 。

我国近些年大力推动生态文明建设,诸如,倡导山水林田湖草生命共同体的系统思维和“绿水青山就是 金山银山” 的发展观念 ${ }^{[29]}$; 组织全国各省份编制 “三线一单 (生态保护红线、环境质量底线、资源利用上线和

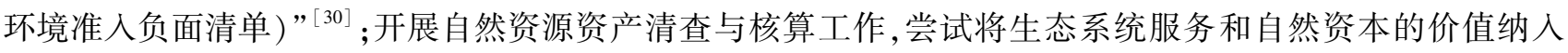
国民核算体系 ${ }^{[31]}$; 建设可持续发展议程国家创新示范区,打造在社会、经济和环境维度上特色高效的可持续 发展范本 ${ }^{[32]}$ 。基于国家可持续发展需求, 我国科研工作者要注重科学研究对决策的支撑, 加强与国际生态社会系统研究动态和议程的衔接,结合联合国可持续发展目标, 探索符合中国国情的人与自然可持续发展 路径。

\section{参考文献 (References) :}

[ 1 ] United Nations Environment Programme. Making Peace with Nature: A Scientific Blueprint to Tackle the Climate, Biodiversity and Pollution Emergencies. Nairobi: UNEP, 2021. https://www. unep. org/gan/resources/report/making-peace-nature-scientific-blueprint-tackle-climatebiodiversity-and-pollution.

[ 2 ] World Bank. Poverty and Shared Prosperity 2020: Reversals of Fortune. Washington, DC: World Bank, 2020.

[ 3 ] IPBES. Summary for Policymakers of the Global Assessment Report on Biodiversity and Ecosystem Services of the Intergovernmental Science-Policy Platform on Biodiversity and Ecosystem Services. Bonn: IPBES, 2019.

[ 4 ] EIA. International Energy Outlook 2020. [2021-03-01]. https://www.eia.gov/outlooks/ieo/.

[ 5 ] IPBES. Summary for Policymakers of the Assessment Report on Land Degradation and Restoration of the Intergovernmental Science-Policy Platform on Biodiversity and Ecosystem Services. Bonn: IPBES, 2018.

[ 6 ] Naidoo R, Fisher B. Reset sustainable development goals for a pandemic world. Nature, 2020, 583(7815) : 198-201.

[ 7 ] IPCC. Intergovernmental Panel on Climate Change Special Report on Global Warming of $1.5^{\circ} \mathrm{C}$. Switzerland: IPCC, 2018.

[ 8 ] United Nations. The Paris Agreement. [2021-03-01]. https://unfccc.int/process-and-meetings/the-paris-agreement/the-paris-agreement.

[ 9 ] Lenton T M, Rockström J, Gaffney O, Rahmstorf S, Richardson K, Steffen W, Schellnhuber H J. Climate tipping points-too risky to bet against. Nature, 2019, 575(7784) : 592-595.

[10] Secretariat of the Convention on Biological Diversity. Global Biodiversity Outlook 5-Summary for Policy Makers. Montréal: CBD, 2020. https:// www.cbd.int/gbo/gbo5/publication/gbo-5-spm-en.pdf.

[11] World Meteorological Organization. Scientific Assessment of Ozone Depletion: 2018. Geneva: WMO, 2018.

[12] United Nations Environment Programme. Global Environment Outlook-GEO-6: Summary for Policymakers. Nairobi: UNEP, 2019.

[13] Shaddick G, Thomas M L, Mudu P, Ruggeri G, Gumy S. Half the world's population are exposed to increasing air pollution. npj Climate and Atmospheric Science, 2020, 3(1): 23 .

[14] Swiss Re Institute. Natural catastrophes and man-made disasters in 2018: “secondary” perils on the frontline. [2021-03-01]. https://www.swissre. com/dam/jcr : c37eb0e4-c0b9-4a9f-9954-3d0bb4339bfd/sigma2_2019_en.pdf.

[15] World Economic Forum. The Global Risks Report 2020. 15th ed. Geneva: WEF, 2020. https://www. weforum. org/reports/the-global-risksreport-2020.

[16] United Nations Environment Programme. Emissions Gap Report 2020: Executive Summary. Nairobi: UNEP, 2020.

[17] 刘炎序, 傅伯杰, 赵文武, 王帅. 生态资产核算与生态系统服务评估: 概念交汇与重点方向. 生态学报, 2018, 38(23): 8267-8276.

[18] Ouyang Z Y, Song C S, Zheng H, Polasky S, Xiao Y, Bateman I J, Liu J G, Ruckelshaus M, Shi F Q, Xiao Y, Xu W H, Zou Z Y, Daily G C. Using gross ecosystem product (GEP) to value nature in decision making. Proceedings of the National Academy of Sciences of the United States of America, 2020, 117(25): 14593-14601.

[19] Hua T, Zhao W W, Wang S, Fu B J, Pereira P. Identifying priority biophysical indicators for promoting food-energy-water nexus within planetary boundaries. Resources, Conservation and Recycling, 2020, 163: 105102.

[20] Kahn L. Perspective: the one-health way. Nature, 2017, 543(7647): S47.

[21] 谢正辉, 刘斌, 延晓冬, 孟春雷, 徐宪立, 刘宇, 秦佩华, 贾炳浩, 谢瑾博, 李锐超, 王龙欢, 王妍, 陈思. 应对气候变化的城市规划实施 效应评估研究. 地理科学进展, 2020, 39(1): 120-131.

[22] Diffenbaugh N S, Field C B, Appel E A, Azevedo I L, Baldocchi D D, Burke M, Burney J A, Ciais P, Davis S J, Fiore A M, Fletcher S M, Hertel T W, Horton D E, Hsiang S M, Jackson R B, Jin X M, Levi M, Lobell D B, McKinley G A, Moore F C, Montgomery A, Nadeau K C, 
Pataki D E, Randerson J T, Reichstein M, Schnell J L, Seneviratne S I, Singh D, Steiner A L, Wong-Parodi G. The COVID-19 lockdowns: a window into the Earth System. Nature Reviews Earth \& Environment, 2020, 1(9) : 470-481.

[23] IPBES. Workshop Report on Biodiversity and Pandemics of the Intergovernmental Science-Policy Platform on Biodiversity and Ecosystem Services. Bonn: IPBES, 2020. https://ipbes.net/pandemics.

[24] Yin C C, Zhao W W, Cherubini F, Pereira P. Integrate ecosystem services into socio-economic development to accelerate achievement of sustainable development goals. Geography and Sustainability, 2021, 2(1): 68-74.

[25] Zhao W W, Zhang J Z, Meadows M E, Liu Y X, Hua T, Fu B J. A systematic approach is needed to contain COVID- 19 globally. Science Bulletin, 2020, 65(11): 876-878.

[26] 李双成. 如何科学衡量自然对人类的贡献——个基于生态系统服务的社会-生态系统分析框架及其应用. 人民论坛 - 学术前沿, 2020 , (11) : 28-35.

[27] 赵文武, 侯炎榛, 刘炎序. 人地系统耦合与可持续发展: 框架与进展. 科技导报, 2020,38(13): 25-31.

[28] Clark W C, Harley A G. Sustainability science: toward a synthesis. Annual Review of Environment and Resources, 2020, 45: $331-386$.

[29] 吴钢, 赵萌, 王辰星. 山水林田湖草生态保护修复的理论支撑体系研究. 生态学报, 2019, 39(23): 8685-8691.

[30] 吕红迪, 万军, 秦昌波, 于雷, 张培培, 张南南, 熊善高, 路路. “三线一单”划定的基本思路与建议. 环境影响评价, 2018, 40(3): 1-4.

[31] 刘高慧, 胡理乐, 高晓奇, 杜乐山, 李俊生, 肖能文. 自然资本的内涵及其核算研究. 生态经济, 2018, 34(4): 153-157, 163-163.

[32］孙新章. 中国建立落实 2030 年可持续发展议程创新示范区的战略思考. 中国人口 - 资源与环境, 2017, 27(4): 1-5. 